\title{
The nature of variations of ammonia proton affinity in an argon
}

\author{
environment
}

\author{
Jaroslaw J. Szymczak, ${ }^{\dagger \ddagger}$ Jan Urban $^{\dagger \S}$ Szczepan Roszak, ${ }^{\dagger \ddagger}$ and Jerzy \\ Leszczynski $^{\dagger *}$
}

\section{Supplementary Material}

Cartesian Coordinates for the $\mathrm{NH}_{4}{ }^{+} \mathrm{Ar}_{\mathrm{n}}(\mathrm{n}=0-5)$ Systems (standard optimization)

$$
\begin{array}{lrrr}
\mathrm{NH}_{4}{ }^{+} \text {(Figure 1a) } \\
& & & \\
1 & -0.806289 & -0.552810 & -0.291309 \\
7 & -0.000003 & -0.000005 & 0.000001 \\
1 & 0.852529 & -0.421689 & -0.368696 \\
1 & -0.091856 & 0.950476 & -0.358779 \\
1 & 0.045634 & 0.024057 & 1.018775
\end{array}
$$

$\mathrm{NH}_{4}^{+} \mathrm{Ar}$ (Figure 1b)
$\mathrm{NH}_{4}^{+} \mathrm{Ar}_{3}$ (Figure 1d)

$$
\begin{array}{rrrr}
1 & -0.000168 & -0.001367 & 1.947193 \\
7 & 0.000180 & -0.001004 & 0.928414 \\
1 & 0.851130 & -0.453716 & 0.587465 \\
1 & -0.817241 & -0.511463 & 0.586969 \\
1 & -0.033141 & 0.962344 & 0.587613 \\
18 & -2.660813 & -1.656051 & -0.188756 \\
18 & -0.105180 & 3.130755 & -0.189170 \\
18 & 2.765890 & -1.474081 & -0.189193
\end{array}
$$

$$
\begin{array}{rrrr}
1 & -2.372414 & -0.768068 & -0.651215 \\
7 & -2.047754 & 0.038994 & -0.119469 \\
1 & -2.444636 & 0.009271 & 0.819207 \\
1 & -1.025909 & 0.019454 & -0.058947 \\
1 & -2.344412 & 0.895264 & -0.586700 \\
18 & 1.251203 & -0.023827 & 0.072996
\end{array}
$$

$\mathrm{NH}_{4}{ }^{+} \mathrm{Ar}_{2}$ (Figure 1c)

$$
\begin{array}{rrrr}
1 & 0.000414 & 2.063960 & 0.832561 \\
7 & -0.000007 & 1.476184 & 0.000000 \\
1 & -0.001043 & 2.065014 & -0.831816 \\
1 & 0.835652 & 0.886039 & -0.001097 \\
1 & -0.834928 & 0.885013 & 0.000352 \\
18 & 2.698974 & -0.450927 & 0.000000 \\
18 & -2.698977 & -0.450924 & 0.000000
\end{array}
$$


Cartesian Coordinates for the $\mathrm{NH}_{3} \mathrm{Ar}_{\mathrm{n}}(\mathrm{n}=0-4)$ Systems

(CP - optimization)

$\mathrm{NH}_{3}$

$\begin{array}{rrrr}7 & 0.000000 & 0.000000 & 0.000000 \\ 1 & 0.000000 & 0.000000 & 1.009837 \\ 1 & 0.966742 & 0.000000 & -0.291801 \\ 1 & -0.391811 & 0.883837 & -0.291680\end{array}$

$\mathrm{NH}_{3} \mathrm{Ar}$ (Figure 2a)

$\begin{array}{rrrr}7 & 0.067322 & 0.007933 & 0.065729 \\ 1 & -0.158892 & 0.383327 & 0.975165 \\ 1 & 0.975393 & 0.370594 & -0.185413 \\ 1 & -0.597433 & 0.394925 & -0.588175 \\ 18 & 2.679190 & -0.279598 & 2.552930\end{array}$

$\mathrm{NH}_{3} \mathrm{Ar}$ (Figure 2b)

$$
\begin{array}{rrrr}
7 & -0.052873 & 0.008403 & 0.020722 \\
1 & -0.053735 & 0.007722 & 1.030240 \\
1 & 0.912523 & 0.014494 & -0.274385 \\
1 & -0.458257 & 0.884454 & -0.274787 \\
18 & 3.698436 & -0.376103 & -1.316290
\end{array}
$$

$\mathrm{NH}_{3} \mathrm{Ar}$ (Figure 2c)

$$
\begin{array}{rrrr}
7 & 0.643940 & -0.076033 & 1.690816 \\
1 & 1.540873 & 0.380200 & 1.771805 \\
1 & 0.767815 & -1.027594 & 2.004479 \\
1 & 0.024224 & 0.373082 & 2.349182 \\
18 & 2.092202 & -0.242881 & 5.493127
\end{array}
$$

$\mathrm{NH}_{3} \mathrm{Ar}_{2}$ (Figure 3a)

$$
\begin{array}{rrrr}
7 & -0.011939 & -0.146317 & 0.217671 \\
1 & -0.642225 & -0.244029 & 1.000443 \\
1 & 0.884401 & -0.505044 & 0.513223 \\
1 & 0.105710 & 0.842953 & 0.053757 \\
18 & 2.764379 & 0.848472 & -1.862990 \\
18 & -0.480103 & 2.872671 & -2.133348
\end{array}
$$

$\mathrm{NH}_{3} \mathrm{Ar}_{2}$ (Figure 3b)

$$
\begin{array}{rrrr}
7 & -0.039375 & -0.116610 & -0.074360 \\
1 & 0.131479 & -0.087790 & 0.920374 \\
1 & 0.834976 & -0.359209 & -0.517280 \\
1 & -0.264267 & 0.825122 & -0.360855 \\
18 & -2.968316 & 1.079617 & 1.673980 \\
18 & 0.192249 & 3.155989 & 2.167298
\end{array}
$$

$\mathrm{NH}_{3} \mathrm{Ar}_{2}$ (Figure 3c)

$$
\begin{array}{rrrr}
7 & -0.282126 & 0.158403 & 0.283025 \\
1 & -0.533671 & 1.051316 & 0.681698 \\
1 & -0.077641 & -0.462869 & 1.052262 \\
1 & 0.580241 & 0.294004 & -0.224281 \\
18 & -0.147282 & 3.023843 & -1.903461 \\
18 & 1.598035 & -2.798941 & -0.578070
\end{array}
$$

$$
\begin{array}{rrrr}
\mathrm{NH}_{3} \mathrm{Ar}_{3} \text { (Figure 4a) } \\
\\
7 & 0.739649 & 0.166562 & 2.477679 \\
1 & 0.389744 & 0.120013 & 3.423805 \\
1 & 0.102276 & -0.363182 & 1.900748 \\
1 & 1.623151 & -0.322279 & 2.465587 \\
18 & 1.927187 & -0.654386 & -0.818836 \\
18 & -0.637026 & 2.157136 & -0.438671 \\
18 & -1.752257 & -1.481888 & -0.159325 \\
& & & \\
\left.\mathrm{NH}_{3} \mathrm{Ar}_{4} \text { (Figure } 4 \mathrm{~b}\right) & & \\
& & & \\
7 & 3.389659 & 0.021162 & 0.091635 \\
1 & 4.205695 & -0.560633 & -0.032265 \\
1 & 2.614324 & -0.461839 & -0.338867 \\
1 & 3.544133 & 0.864023 & -0.442551 \\
18 & 0.285271 & -0.738216 & 2.086319 \\
18 & 0.134132 & -1.552318 & -1.637428 \\
18 & 0.489003 & 2.077976 & -0.481130 \\
18 & -2.802393 & 0.213131 & 0.041808
\end{array}
$$




$\begin{array}{rrrr}\mathrm{NH}_{4}{ }_{4}^{+} \mathrm{Ar}_{4} \text { (Figure 1e) } & \\ & & & \\ 1 & -0.808162 & -0.555852 & -0.292886 \\ 7 & -0.000449 & -0.002110 & -0.001033 \\ 1 & 0.853607 & -0.424434 & -0.370402 \\ 1 & -0.092394 & 0.950043 & -0.360429 \\ 1 & 0.045301 & 0.022083 & 1.019512 \\ 18 & -0.301244 & 3.108347 & -1.170803 \\ 18 & 0.152585 & 0.078356 & 3.331207 \\ 18 & 2.789524 & -1.377455 & -1.208692 \\ 18 & -2.640599 & -1.807974 & -0.951077\end{array}$

$\mathrm{NH}_{4}{ }^{+} \mathrm{Ar}_{5}$ (Figure 1f)

$\begin{array}{rrrr}1 & 1.593874 & -0.002914 & 0.002854 \\ 7 & 0.570233 & -0.001023 & 0.001110 \\ 1 & 0.224274 & -0.648470 & -0.712500 \\ 1 & 0.222117 & -0.293834 & 0.918277 \\ 1 & 0.226388 & 0.941169 & -0.204219 \\ 18 & -0.545100 & -0.974235 & 3.048807 \\ 18 & -0.528247 & 3.130610 & -0.681815 \\ 18 & -0.537147 & -2.157686 & -2.365870 \\ 18 & 3.963600 & -0.004612 & 0.003853 \\ 18 & -2.700787 & 0.006546 & -0.005652\end{array}$

